

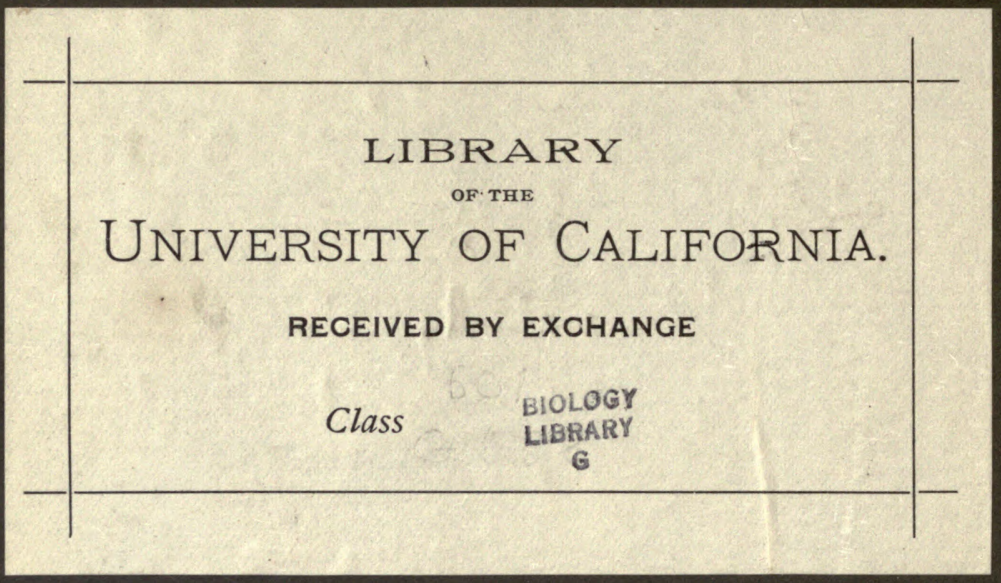


The University of Chicago FOUNI)ED BY JOHN D. ROCKEF ELLER

\section{VARIATION AND CARBOHYDRATE METABOLISM OF BACILLI OF THE PROTEUS GROUP.}

\section{A DISSERTATION \\ SUBMITTED TO THE FACULTY \\ OF THE}

OGDEN GRADUATE SCHOOL OF SCIENCE

IN CANDIDACY FOR THE DEGREE OF

DOCTOR OF PHILOSOPHY

(DEPARTMENT OF BACTERIOLOGY)

BY

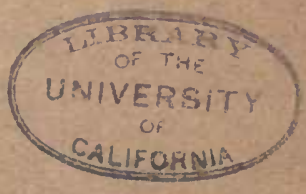

THOMAS HAIGH GLENN

CHICA GO

1911 

The University of Chicago FOUNDED BY JOHN D. ROCKEFELLER

\section{VARIATION AND CARBOHYDRATE METABOLISM OF BACILLI OF THE PROTEUS GROUP.}

\section{A DISSERTATION}

SUBMITTED TO THE FACULTY

OF THE

OGDEN GRADUATE SCHOOL OF SCIENCE

IN CANDIDACY FOR THE DEGREE OF

DOCTOR OF PHILOSOPHY

(DEPARTMENT OF BACTERIOLOGY)

BY

THOMAS HAIGH GLENN

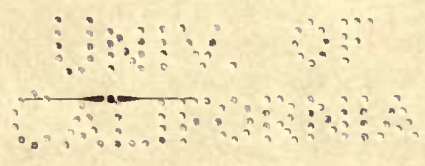

CHICAGO

1911 


$$
\begin{aligned}
& \text { QR82 } \\
& \text { B } 37 G 6
\end{aligned}
$$

BIOLOGY

LIBRARY

$$
\text { C }
$$

$$
\begin{aligned}
& \because 60 \\
& \text { a } 190 \%
\end{aligned}
$$




\section{Introduction.}

It has been shown by many observers that changes in the chemical and physical environment of micro-organisms lead to marked variations, not only in the morphology of the cell, but also in its physiological activities. The variations in the form and staining characteristics of B. diph theriae, the formation of long and short chains in the Streptococci, the appearance of capsules, the production of spores and development of involution forms in old cultures indicate the readiness with which unicellular organisms respond to their external environment.

The facility with which micro-organisms change their form and the mechanical difficulties involved in the observation of variations in their morphology, renders any classification of bacteria based on morphology alone very unsatisfactory. Recently, the bio-chemical characteristics of bacteria have played an important part in the study of bacterial species. The physiological activities of bacteria in different cultural media are easily studied, and under a uniform set of conditions many of the characteristics of species exhibit a remarkable degree of constancy. If uniform conditions are not adhered to, however, variations may be obtained.

Péré (1) in his researches on lactic acid produced by microorganisms found that the same organism may produce lactic acid of the opposite optical activity, according to the quantity and the quality of the protein used. The correctness of this observation has, however, been questioned by later workers. Kruse (2) found that Staphylococci lose their liquefying power after prolonged cultivation under anaerobic conditions. Andrewes and Horder (3) record a case where Streptococci refused to attack lactose under ordinary conditions, but did so readily under anaerobic conditions. Conn (4) starting with a pure culture of a micrococcus was able to obtain by simply replating many times and selecting from the number of colonies on the plate, the one which liquefied most rapidly and the one which liquefied most slowly, a rapidly liquefying culture and one which hardly liquefied at all. $\mathrm{S} m$ ith (5) records similar results with Prote us vulgaris. Peckham (6) has shown that organisms that may not have the power to produce indol may develop this power if allowed to grow in suitable media. Tw ort (7), by growing organisms in a fluid medium containing a sugar that they had not been previously able to ferment, was able to cause these organisms to ferment the sugar. Goodman (8) states that he was able by a gradual process of selection of impressed variations, 
to modify greatly the acid producing characteristics of the diphtheria group of organisms.

The present paper is a report of the results of an investigation upon the variation and carbohydrate metabolism of the bacilli of the Proteus group. In view of the fact that this group of organisms is found widely distributed under varied conditions in nature, it offers a promising field for investigation.

\section{Historical.}

The members of this group of micro-organisms were first isolated by $\mathrm{Hauser}(9)$ who regarded them as the chief bacteria concerned in the process of putrefaction. He isolated three forms which he originally regarded as distinct species, but his later observations led him to believe that all three forms are but varieties of the same species. Since then, they have been isolated many times from sewage by many different investigators. Schnitzer (10) isolated a nember of the Proteus group from a case of cystitis. Flexner (11) found it in a case of peritonitis, and Reed (12) found a Prote us organism associated with the P ne u mococ cus in a case of croupous pneumonia. Levy (13) isolated a Proteus form from a sample of beer yeast. Wyss (14) obtained B. vulgar is from dead fish. Silberschmidt (15), Gluckman (16), and others have isolated members of the group from infected meat.

W ard (18) studied a number of organisms of this group which he isolated from the Thames and came to the conclusion that Ha $\mathrm{Her}$ 's three species of Proteus, together with several others isolated by himself, are merely variations of one species. He considers them similar in size and form, mode of growth, formation of zooglea, etc., but as varying in detail as to rapidity of growth and liquefaction, and consequent differences in the extent and appearance of the colony, and as to the intensity of pigmentation. Fuller and Johnson (19) regard all nonfluorescent, non-chromogenic gelatin liquefying bacteria forming proteuslike colonies on gelatin, as belonging to the Proteus group. Ford (20) includes under the Proteus group all organisms which liquefy blood serum, casein, and gelatin, produce cloudiness in broth but no scum, render milk acid, then alkaline, and which ferment dextrose with gas formation. J o r d a n (21) includes under the P r o t e us group, organisms which ferment sucrose and dextrose, rarely lactose, which are for the most part vigorously proteolytic, rapidly liquefying gelatin and blood serum and precipitating and then dissolving casein.

All of the above authors seem to lay special stress on the proteolytic and fermentative properties of this group. It becomes essential, therefore, to endeavour to establish the factors which may influence either one of these characteristics.

\section{Source of cultures.}

The organisms used in this investigation were obtained from the laboratories of the University of Michigan, University of Pennsylvania, University of Illinois, University of Chicago, the laboratory of the Public Health and Marine Hospital Service, Washington and from Král's laboratory.

All cultures were rejuvenated according to the method of $\mathrm{Fuller}$ and Johnson. Transfers were made from the gelatin plates to slant agar. These were incubated for 24 hours and used to inoculate all the 
ordinary media. The cultural characteristics of each organism are given in table No. 1.

It will be seen from an examination of the table that acid is produced readily by some of the cultures, while others produce very little or none at all. If the acid producing cultures and the non-acid producing organisms of this group belong to the same species, it was thought possible to produce by selection from the descendants of the acid producing variety an organism which would produce acid readily and one which would not produce acid at all. Cultures 1 and 2 were selected. These were plated out in gelatin and typical colonies were fished out and transferred to slant agar tubes. These tubes were incubated for 24 hours and at the end of that time a sub-culture in broth was made, and from each of the 24 hour broth cultures a single bacillus was obtained by Barber's method (22). This was done in order to make sure that all of the organisms would be descendants of a single cell, so that the individual inheritance might be studied instead of averages.

G o o d man, in his experiments with diphtheria bacilli made transfers direct from sugar broth to sugar broth. The direct influence of environment, as has been pointed out by Winslow and Walker (23), was not entirely excluded. These authors attempted to exclude this factor in their study of the variations in the paratyphoid bacillus by plating out each culture on a series of gelatin plates and inoculating 100 agar tubes from 100 separate colonies of each strain. Dextrose broth tubes were then inoculated from the agar slants and the acidity in each of the sugar broth tubes was determined by titration after 72 hours. Instead of making further inoculations from the broth tubes, those agar cultures were selected which in broth had shown the highest acidity for their respective types. These were plated out and from the colonies on the plates new agar streaks were made.

W in slow and W alker (23), while excluding the factor of environment, carried their cultures through three generations only and thus did not get the benefit of the accumulation of differences which might have taken place if the number of transfers had been increased.

In the present investigation, the cultures derived from a single cell were plated out and three series of cultures were made. In the first series, twenty separate colonies were isolated and inoculated into twenty sugar-free broth tubes to which $1 \%$ of dextrose had been added. After three days incubation at $37^{\circ}$, the acidity was determined by titration with $\frac{\mathrm{n}}{10} \mathrm{NaOH}$, using phenolphthalein as an indicator. The tube giving the maximum acidity and that showing the minimum acidity were plated out and the dextrose broth tubes were inoculated from each of the plates, a separate colony being fished out for each tube.

In the second series, the cultures were plated out and 10 agar tubes were inoculated from ten separate colonies. These tubes where incubated for 24 hours at $37^{\circ} \mathrm{C}$. and a tube of $1 \%$ dextrose broth was inoculated from each. The dextrose tubes were incubated at $37^{\circ} \mathrm{C}$. for three days and titrated as in the first series. The tubes giving the maximum and minimum of acid were selected. Wishing to avoid all chances of dealing with organisms that might have acquired some tolerance to degrees of acidity produced in the medium by their own growth, all such were discarded; but the two agar streaks derived from the races that had shown the highest and the lowest acidity for their respective types, were 
used. These streaks were plated out and from the colonies on the plates new agar streaks were made and dextrose broth tubes inoculated from these as before. In no case either in the plate or on the agar slant was the culture allowed to come in contact with sugar until inoculated into broth.

In the third series of cultures, the cultures were plated out as in the other series, but the colonies were transferred direct to broth tubes containing $1 \%$ of dextrose. The acidity was determined as before, but in this series the culture in the tubes producing the highest and the lowest amount of acidity were inoculated direct into sugar broth without plating out, except to determine the purity of the cultures.

In the tables are given the averages of the acid produced in the high and low series. In most cases, the organism selected in the high series produced a higher percentage of acid than the average, and the organism selected in the low series produced a lower percentage of acidity than is shown by the average of the series, but any true variation should be transferred to all of the descendants, so that the average percentage of acid produced represents a fairly good index of the variation of the acid producing power of the organism. From these tables, it is

Proteus vulgaris 1.

\begin{tabular}{|c|c|c|c|c|c|c|}
\hline \multirow{2}{*}{ No. } & \multicolumn{2}{|c|}{ Series I } & \multicolumn{2}{|c|}{ Series II } & \multicolumn{2}{|c|}{ Series III } \\
\hline & High & Low & High & Low & High & Low \\
\hline 1 & 2.29 & 2.29 & 2.29 & 2.29 & 2.35 & 2.35 \\
\hline 2 & 2.30 & 2.28 & 2.25 & 2.22 & 2.37 & 2.29 \\
\hline 3 & 2.34 & 2.31 & 2.40 & 2.11 & 2.19 & 2.19 \\
\hline 4 & 2.35 & 2.29 & 2.29 & 2.30 & 2.28 & 2.17 \\
\hline 5 & 2.4 & 2.35 & 2.30 & 2.28 & 2.34 & 2.30 \\
\hline 6 & 2.33 & 2.1 & 2.35 & 2.25 & 2.14 & 2.05 \\
\hline 7 & 2.2 & 2.05 & 2.31 & 2.17 & 1.98 & 1.93 \\
\hline 8 & 1.9 & 1.85 & 1.96 & 1.93 & 2.08 & 1.98 \\
\hline 9 & 2.17 & 2.05 & 1.96 & 1.96 & 2.05 & 2.05 \\
\hline 10 & 1.91 & 1.95 & 1.98 & 1.94 & 2.07 & 2.08 \\
\hline 11 & 1.95 & 1.92 & 2.22 & 2.20 & 2.14 & 2.11 \\
\hline 12 & 1.93 & 1.9 & 1.93 & 1.94 & 2.03 & $1: 98$ \\
\hline 13 & 2.03 & 2.03 & 2.00 & 2.04 & 1.91 & 1.90 \\
\hline 14 & 2.15 & 2.03 & 1.90 & 1.89 & 1.90 & 1.89 \\
\hline 15 & 2.13 & 2.07 & 2.16 & 2.07 & 1.88 & 1.86 \\
\hline 16 & 2.09 & 2.09 & 2.14 & 2.12 & 1.80 & 1.78 \\
\hline 17 & 2.05 & 2.07 & 2.08 & 2.01 & 1.80 & 1.78 \\
\hline 18 & 1.91 & 1.86 & 2.02 & 2.00 & 1.63 & 1.64 \\
\hline 19 & 1.97 & 1.88 & 1.72 & 1.64 & 1.65 & 1.65 \\
\hline 20 & 1.94 & 1.81 & 1.73 & 1.66 & 2.00 & 1.99 \\
\hline 21 & 1.94 & 1.85 & 1.58 & 1.48 & 1.82 & 1.72 \\
\hline 22 & 1.75 & 1.73 & 1.60 & 1.59 & 1.73 & 1.71 \\
\hline 23 & 1.74 & 1.71 & 1.74 & 1.65 & 1.94 & 1.85 \\
\hline 24 & 1.72 & 1.68 & 1.82 & 1.88 & 2.02 & 1.96 \\
\hline 25 & 1.55 & 1.49 & 2.01 & 1.97 & 1.97 & 1.96 \\
\hline 26 & $1 . \overline{8} 8$ & 1.56 & 1.69 & 1.67 & 1.99 & 1.98 \\
\hline 27 & 1.61 & 1.53 & 1.70 & 1.61 & 2.03 & 2.01 \\
\hline 28 & 1.66 & 1.61 & 1.71 & 1.80 & & \\
\hline 29 & 1.62 & 1.63 & & & & \\
\hline 30 & 1.72 & 1.68 & & & & \\
\hline 31 & 2.03 & 1.92 & & & & \\
\hline 32 & 1.76 & 1.71 & & & & \\
\hline 33 & 2.07 & 2.03 & & & & \\
\hline 34 & 1.69 & 1.68 & & & & \\
\hline 35 & 1.75 & 1.75 & & & & \\
\hline
\end{tabular}


Proteus vulgaris II.

\begin{tabular}{|c|c|c|c|c|}
\hline \multirow{2}{*}{ No. } & \multicolumn{2}{|c|}{ Series I } & \multicolumn{2}{|c|}{ Series II } \\
\hline & High & Low & High & Low \\
\hline 1 & 2.3 & 2.3 & 2.4 & 2.4 \\
\hline 2 & 2.2 & 2.18 & 2.4 & 2.37 \\
\hline 3 & 2.3 & 2.3 & 2.20 & 2.16 \\
\hline 4 & 2.38 & 2.28 & 2.08 & 2.12 \\
\hline 5 & 2.38 & 2.41 & 2.02 & 1.94 \\
\hline 6 & 1.97 & 1.91 & 1.87 & 1.78 \\
\hline 7 & 2.12 & 2.14 & 2.04 & 1.96 \\
\hline 8 & 1.84 & 1.78 & 1.90 & 1.90 \\
\hline 9 & 1.89 & 1.83 & 1.99 & 2.01 \\
\hline 10 & 1.9 & 1.86 & 2.1 & 1.84 \\
\hline 11 & 2.04 & $\begin{array}{l}1.99 \\
\end{array}$ & 2.00 & 1.84 \\
\hline 12 & 1.89 & 1.86 & 1.91 & 1.88 \\
\hline 13 & 1.93 & 1.92 & 2.15 & 2.10 \\
\hline 14 & 1.88 & 1.88 & 1.78 & 1.75 \\
\hline 15 & 1.95 & 1.91 & 1.87 & 1.86 \\
\hline 16 & 2.02 & 1.93 & 1.79 & 1.77 \\
\hline 17 & 1.92 & 1.89 & 1.66 & 1.55 \\
\hline 18 & 1.63 & 1.65 & 1.68 & 1.68 \\
\hline 19 & 1.7 & 1.69 & 1.83 & 1.81 \\
\hline 20 & 1.68 & 1.69 & 1.95 & 2.09 \\
\hline 21 & 1.51 & 1.5 & 1.72 & 1.68 \\
\hline 22 & 1.52 & 1.56 & 1.97 & 1.94 \\
\hline 23 & 1.60 & 1.64 & 2.04 & 2.00 \\
\hline 24 & 1.77 & 1.81 & 1.96 & 1.80 \\
\hline 25 & 1.56 & 1.57 & 2.02 & 1.99 \\
\hline 26 & 1.57 & 1.59 & 1.91 & 1.90 \\
\hline 27 & 1.68 & 1.56 & 1.92 & 1.91 \\
\hline 28 & 1.82 & 1.8 & 1.92 & 1.90 \\
\hline 29 & 1.98 & 1.83 & & \\
\hline 30 & $1.9 \cdot 2$ & 1.91 & & \\
\hline 31 & 1.86 & 1.83 & & \\
\hline 32 & 1.91 & 1.88 & & \\
\hline
\end{tabular}

evident that very little, if any, modification of either of the organisms has taken place as a result of the selection of slight variations in acid production. In all cases, there is a slight decrease in the power to produce acid, but this may be explained by the fact that the organism in some cases was in contact with acid so long that all of its powers may have been inhibited. In the cases where they did not come in contact with acid at all, the power to ferment sugar was gradually decreasing as a result of growth on sugar-free media. The latter conclusion seems - justifiable on account of the fact that organisms which have been grown on sugar-free media for some time developed a higher power of acid production when cultivated for a short time on media containing sugar, although this power could be decreased again if the growth on sugar media was prolonged, due to coming in contact with acids produced by the fermentation of the sugar.

Since, selection of slightly impressed variation in organisms Nos. 1 and 2 failed to produce a non-acid producing culture, the cultures which orginally produced no acid were grown on media containing $2 \%$ of dextrose for varying lengths of time. I succeeded in getting two cultures to produce acid, but all the other cultures labeled Zenkeri and mirabilis failed to produce any degree of acidity after prolonged cultivation on sugar media. It is possible that continued transferring of these organisms from sugar broth to sugar broth would cause them either to 
Table I.

\begin{tabular}{|c|c|c|c|c|c|c|c|c|c|c|c|}
\hline \multirow{3}{*}{ 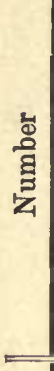 } & \multirow{3}{*}{$\begin{array}{l}\text { Name of } \\
\text { organism }\end{array}$} & \multirow{3}{*}{ Source } & \multirow{2}{*}{\multicolumn{4}{|c|}{ Morphology }} & \multicolumn{5}{|r|}{ Cultura } \\
\hline & & & & & & & \multicolumn{2}{|c|}{$\begin{array}{l}\text { Nutrient } \\
\text { broth tube }\end{array}$} & \multicolumn{2}{|c|}{$\begin{array}{l}\text { Nutrient } \\
\text { agar tube }\end{array}$} & \multirow{2}{*}{ 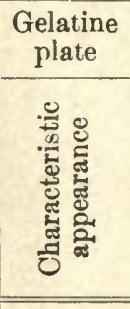 } \\
\hline & & & 㽕 & 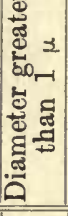 & 䒿 & 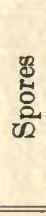 & $\begin{array}{l}\Xi \\
\text { J } \\
\text { ్ֶ }\end{array}$ & 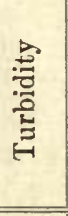 & Еี & $\begin{array}{l}\frac{D}{d} \\
\frac{1}{3} \\
3\end{array}$ & \\
\hline 1 & B. vulgaris I & U. of Chicago & + & - & + & - & - & + & - & - & + \\
\hline 2 & B. $\quad$ II & $n \pi \quad n$ & + & - & + & - & - & + & - & - & + \\
\hline 3 & B. mirabilis & $n$ & + & - & + & - & - & + & - & - & + \\
\hline 4 & B. Zenkeri & $n \pi$ & + & - & + & - & - & + & - & - & + \\
\hline 5 & B. cloacae I & $n n$ & + & 二 & + & - & 一 & + & - & - & 一 \\
\hline $\begin{array}{l}6 \\
7\end{array}$ & $\begin{array}{lll}\text { B. } & n & \text { II } \\
\text { B. } & \text { III }\end{array}$ & $n \pi \quad n$ & $\stackrel{+}{+}$ & $\overline{-}$ & $\stackrel{t}{+}$ & - & - & + & 二 & - & $\bar{z}$ \\
\hline 8 & B. $n$ & Blood of Eng. Sparrow & + & - & + & - & - & + & 二 & - & $\overline{-}$ \\
\hline 9 & B. vulgaris & Hygienic Lab. & + & - & + & - & - & + & - & - & + \\
\hline 10 & B. mirabilis & $n \quad n$ & + & - & + & 一 & - & + & 一 & - & + \\
\hline 11 & B. Zenkeri & $n \quad n$ & + & - & + & - & - & + & - & - & + \\
\hline 12 & $\begin{array}{l}\text { B. cloacae } \\
\text { B. vulgaris }\end{array}$ & U. of Mich. & $\begin{array}{l}+ \\
+\end{array}$ & - & $t$ & - & - & $\begin{array}{l}+ \\
+\end{array}$ & $\overline{-}$ & $\bar{z}$ & $\overline{1}$ \\
\hline 14 & $\begin{array}{l}\text { B. vulgaris } \\
\text { B. }\end{array}$ & U. of Illinois & + & - & + & - & - & + & - & - & + \\
\hline 15 & B. Zopfi & & + & - & + & - & - & + & - & - & + \\
\hline 16 & B. vulgaris & U. of Penn. & + & - & + & - & - & + & - & - & + \\
\hline 17 & B. mirabilis & $n n \quad n$ & + & - & + & - & 一 & + & - & - & + \\
\hline 18 & B. Zenkeri & $n n \quad "$ & + & 一 & + & 一 & 一 & + & - & - & + \\
\hline $\begin{array}{l}19 \\
20\end{array}$ & $\begin{array}{l}\text { B. cloacae } \\
\text { B. vulgaris }\end{array}$ & Ǩral's Lab. & $\stackrel{+}{+}$ & 二 & + & - & - & + & $\overline{-}$ & $\bar{z}$ & $\bar{t}$ \\
\hline 21 & B. mirabilis & $n \quad n$ & + & - & + & - & - & + & - & - & + \\
\hline 22 & B. Zenkeri & $n$ & + & - & + & - & - & + & - & - & + \\
\hline 23 & B. Zopfi & $\pi$ & + & - & + & - & - & + & 一 & 一 & + \\
\hline 24 & B. cloacae & $\pi$ & + & - & + & - & - & + & - & - & - \\
\hline
\end{tabular}

regain their power of acid production or develop this power. A series of 20 transfers with a lapse of two days between each failed to cause them to ferment sugar to any appreciable degree. It should be stated, however, that all the organisms labeled Zopfii, Zenkeri, and mirabilis, with the exception of Nos. 3 and 17 , grew very sparingly on all the laboratory media, although all gave the characteristic colonies on gelatin plates.

All the organisms which fermented dextrose readily, fermented saccharose, mannose, and galactose, but failed to ferment lactose, even when grown in lactose broth for several days. In the fermentation tubes containing lactose broth inoculated with these organism, there appeared good growth in the open arm, but none whatever in the closed arm. This suggested the idea that it is much easier for these organisms to get their oxygen from the air than from lactose and, therefore, this sugar is not attacked. If this conclusion were correct, it was thought possible to cause the non-lactose fermenting organisms to ferment this sugar if they were deprived of all other sources of oxygen.

Flasks each containing 100 c.c. of sugar free broth, to which $2 \%$ of lactose had been added, were inoculated with strains of Prote u s vulgaris which had failed repeatedly to ferment lactose under aerobic 
Table I.

\begin{tabular}{|c|c|c|c|c|c|c|c|c|c|c|c|c|c|c|c|c|c|c|c|c|c|}
\hline & & & & & & & & & & $\log$ & & & & & & & & & & & \\
\hline feat & ures & & & & & & & & & & & Bioc & hem & ical & fea & tures & & & & & \\
\hline & $\begin{array}{l}\text { elati } \\
\text { stab }\end{array}$ & & $\begin{array}{r}\text { Pot } \\
\text { tu }\end{array}$ & & $\begin{array}{c}\text { Ferment. } \\
\text { tube }\end{array}$ & & $\frac{0}{0}$ & & & & & proc & $\begin{array}{l}\text { Gas } \\
\text { duct }\end{array}$ & & & & & Milk & & & $\begin{array}{l}\text { Nutrie } \\
\text { agar tul }\end{array}$ \\
\hline 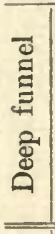 & 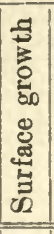 & 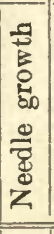 & $\frac{\stackrel{0}{\frac{0}{0}}}{\stackrel{0}{\frac{D}{b}}}$ & 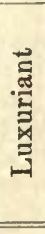 & 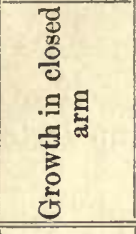 & 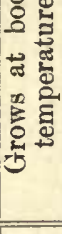 & 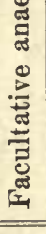 & 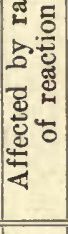 & & 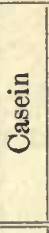 & 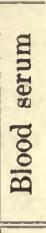 & 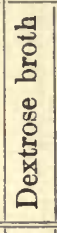 & 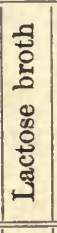 & 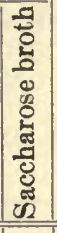 & 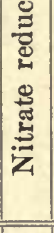 & 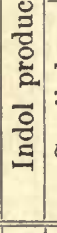 & 胥 & 兑 & 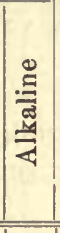 & 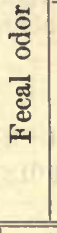 & 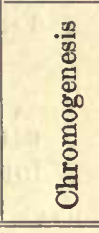 \\
\hline+ & & & & & + & + & & + & + & & & & & & + & +1 & $1+$ & - & & & \\
\hline+ & + & + & + & + & + & + & + & + & + & + & + & + & - & + & + & + & + & - & + & + & - \\
\hline+ & + & + & + & + & + & + & + & + & + & + & + & - & - & - & + & + & + & - & + & + & - \\
\hline \pm & + & + & + & - & + & \pm & + & + & - & - & - & - & - & - & - & - & - & - & + & - & - \\
\hline \pm & + & + & + & + & + & + & + & \pm & $+\mathbf{S}$ & - & - & + & + & + & - & - & + & + & - & \pm & - \\
\hline \pm & + & + & + & + & + & + & + & \pm & $+\mathbf{S}$ & - & - & + & - & + & - & - & + & + & - & \pm & - \\
\hline+ & + & + & + & + & + & + & + & \pm & $+\mathrm{S}$ & - & - & + & - & + & - & - & + & + & - & \pm & \\
\hline+ & + & + & + & + & + & + & + & \pm & $+S$ & - & - & + & + & $1+$ & - & - & + & + & - & + & - \\
\hline+ & + & + & + & + & + & + & + & + & + & + & + & + & + & + & + & + & + & - & + & \pm & - \\
\hline- & + & + & + & - & + & + & + & + & - & - & - & - & - & - & - & - & - & - & - & & \\
\hline- & + & + & + & - & - & \pm & + & + & - & - & - & - & - & - & - & - & - & - & - & - & - \\
\hline- & + & + & + & + & + & + & + & + & $+\mathbf{S}$ & - & - & + & + & + & - & - & + & + & - & + & \\
\hline+ & + & + & + & + & + & + & + & + & + & + & + & + & - & + & + & + & + & - & + & + & - \\
\hline+ & + & + & + & + & + & + & + & + & + & + & + & + & - & + & + & + & + & - & + & + & \\
\hline $\bar{I}$ & $\stackrel{+}{+}$ & + & 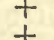 & $\bar{t}$ & $\bar{t}$ & $\stackrel{ \pm}{+}$ & + & + & $\bar{t}$ & $\bar{t}$ & $\bar{t}$ & $\bar{t}$ & $\overline{-}$ & $\bar{t}$ & $\bar{t}$ & $\overline{+}$ & $\bar{t}$ & $\bar{t}$ & $\bar{t}$ & $\overline{+}$ & - \\
\hline$I$ & + & + & + & + & I & t & + & + & + & + & $\dot{t}$ & 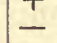 & - & \pm & + & + & t & - & + & & \\
\hline - & + & + & + & - & - & & + & + & - & - & - & - & - & - & - & - & - & - & - & - & - \\
\hline+ & + & + & + & + & + & & + & + & + & - & - & + & + & + & - & - & + & - & + & + & \\
\hline+ & + & + & + & + & + & & + & + & + & + & + & + & - & + & + & + & + & - & + & & - \\
\hline- & $t$ & + & + & & - & + & + & + & - & - & - & - & - & - & - & - & - & - & - & - & \\
\hline- & + & + & + & - & - & $\frac{ \pm}{ \pm}$ & + & + & - & - & - & - & 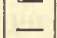 & $\bar{z}$ & - & Z & - & 二 & E & - & - \\
\hline+ & $1+$ & $1+$ & + & + & + & + & + & + & + & - & - & $1+$ & $1+1$ & $1+$ & -1 & $|-|$ & $1+$ & +1 & $1-$ & -1 & 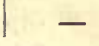 \\
\hline
\end{tabular}

conditions. The flasks were then placed in jars from which the oxygen had been removed by pyrogallic acid and $\mathrm{NaOH}$. The jars were allowed to stand at room temperature for 6 days, when the flasks were removed and their contents titrated against $\frac{\mathrm{N}}{20} \mathrm{NaOH}$ to determine the acidity. In every case, fermentation had taken place as was shown by the difference between the acid in the inoculated tube and that of a sterile control which was placed under anaerobic conditions with the inoculated flasks. The amount of acid produced was increased by inoculating a loopful of broth obtained from the lactose broth flask which showed slight amount of fermentation, into another lactose broth flask containing 100 c. c. of broth. These were placed under anaerobic conditions as in the previous case and tested after 6 days. The experiment was carried through five generations and the results are shown in the following table.

Duplicate flasks grown under aerobic conditions at the same temperature, failed to develop any acid. Fermentation tubes inoculated with these three strains of Proteus and placed under anaerobic conditions showed a growth not only in the open arm, but also in the closed one. This would seem to indicate that Proteus vulgaris can obtain its oxygen from the air much more easily than from lactose, but when it 
Table No. 2.

\begin{tabular}{c|c|c|c|c|c}
\hline \hline Organism & $\begin{array}{c}\text { Per cent. } \\
\text { of acid after } \\
\text { 1st transfer }\end{array}$ & $\begin{array}{c}\text { Per cent. } \\
\text { of acid after } \\
\text { 2d transfer }\end{array}$ & $\begin{array}{c}\text { Per cent. } \\
\text { of acid after } \\
\text { 3d transfer }\end{array}$ & $\begin{array}{c}\text { Per cent. } \\
\text { of acid after } \\
\text { 4th transfer }\end{array}$ & $\begin{array}{c}\text { Per cent. } \\
\text { of acid after } \\
\text { 5th transfer }\end{array}$ \\
\hline \hline Control vulgaris I & 0 & 0 & 0 & 0 & 0 \\
Proteus vulg & 0.6 & 1 & 0.8 & 1 & 1.2 \\
$"$ " II & 0.6 & 1 & 0.8 & 0.8 & 1.3 \\
", 13 & 0.6 & 1 & 1 & 1.9 & 5.1
\end{tabular}

can no longer obtain oxygen from the air it splits up lactose with acid formation.

\section{Effect of earbohydrates on protein metabolism.}

Protein digestion may, according to $\mathrm{Peckham}$ (6), be approximately estimated in many members of the colon group by the production of indol. Péré (1) states that a positive reaction for indol proves the disappearance of sugar in the media. Grape sugar, Kruse (2) thinks, is responsible for the variation in indol production, although he does not state whether the variation is produced by the sugar itself or its decomposition products. S mith (5) thinks the absence of indol in sugar media is due to the presence of acid. Where acid is present no indol is produced, but where acid is absent indol may be formed. A u e r bach (24) showed that the acid products of fermentation set up by certain bacteria inhibit the formation of the proteolytic ferment. Kalischer (25), in experiments to determine whether the splitting of casein is due to the ferment or the living cell, found that the ferment was able to produce peptone, leucin, tyrosin, as well as ammonia and oxyacids, and is in all probability a tryptic ferment. Cacace (26) came to the conclusion that proteolysis in bacteria is similar to that in higher animals. Wherry (27), working with the cholera spirillum, found that acids produced from glucose, maltose and saccharose rapidly killed the cholera spirillum, while those from lactose and starch are not toxic. This author seems to think that the proteolytic ferment of the cholera spirillum is a tryptic ferment. Marshall (28) observed that Bacillus coli grown at $37^{\circ} \mathrm{C}$ for five days in 100 c.c. of peptone beef broth containing $20 \%$ of lactose failed to produce indol.

From experiments already cited, it is evident that Proteus vul $\mathrm{g}$ a ris, under aerobic conditions, does not produce acid in lactose media, while acid is readily produced in dextrose broth. If $\mathrm{S} \mathrm{mith's} \mathrm{conclusion}$ were correct, it was thought that dextrose or any other sugar which can be fermented by Proteus vulgaris, should inhibit the production of indol, while lactose or any other carbohydrate not fermented by this organism should have no effect on indol production. A series of flasks were prepared, each containing about 100 c.c. of distilled water, to which the percentage of peptone and carbohydrate given in the table had been added. Each flask was inoculated with one loopful of a homogeneous suspension of the bacilli and placed in the incubator at $37^{\circ}$. Five c.c. of broth was removed after 48 hours and 24 hours thereafter for 8 days, and tested for indol with paradimethyl benzaldehyde solution ${ }^{1}$ ).

1) 4 parts paradimethyl benzaldehyde.

80 " hydrochloric acid.

$360 "$ alcohol, $95 \%$. 
Table No. 3.

Effect of carbohydrates on the production of indol.

\begin{tabular}{|c|c|c|c|c|c|c|c|c|c|c|c|c|c|c|c|c|}
\hline \multirow{3}{*}{ 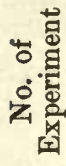 } & \multirow{3}{*}{\multicolumn{2}{|c|}{ Organism }} & \multirow{3}{*}{ 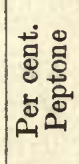 } & \multirow{3}{*}{ 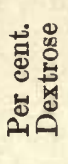 } & \multirow{3}{*}{ 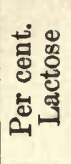 } & \multirow{3}{*}{ 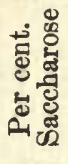 } & \multirow{3}{*}{ 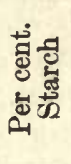 } & \multirow{3}{*}{ 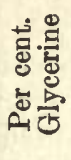 } & \multicolumn{8}{|c|}{ Indol produced } \\
\hline & & & & & & & & & \multicolumn{8}{|c|}{ Hours } \\
\hline & & & & & & & & & 48 & 72 & 96 & 120 & 144 & 168 & 192 & 216 \\
\hline & I & & & & & & & & & & & & & & & \\
\hline 1 & Prot. $\nabla$ & vulg. & 0.5 & 0 & 0 & 0 & 0 & 0 & + & + & + & + & + & + & + & + \\
\hline 2 & $"$ & $"$ & 1 & 0 & 0 & 0 & 0 & 0 & + & + & + & + & + & + & + & + \\
\hline 3 & $"$ & $"$ & 2 & 0 & 0 & 0 & 0 & 0 & $t$ & \pm & + & \pm & + & + & + & + \\
\hline $\begin{array}{l}4 \\
5\end{array}$ & $"$ & $"$ & 0.0 & $\begin{array}{l}0.5 \\
0.5\end{array}$ & 0 & 0 & 0 & 0 & - & - & E & - & - & - & - & 二 \\
\hline 6 & , & $"$ & 2 & 0.5 & 0 & 0 & 0 & 0 & - & - & - & - & - & - & - & - \\
\hline 7 & $"$ & $"$ & 1 & 1 & 0 & 0 & 0 & 0 & - & - & - & - & - & - & - & - \\
\hline 8 & $"$ & ", & 2 & 1 & 0 & 0 & 0 & 0 & - & - & - & - & - & - & - & - \\
\hline 9 & 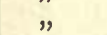 & " & 2 & 2 & 0 & 0 & 0 & 0 & - & - & - & - & - & - & - & - \\
\hline 10 & $"$ & $"$ & 0.5 & 0 & 0.5 & 0 & 0 & 0 & + & + & + & + & + & + & + & + \\
\hline 11 & $"$ & $"$ & 0.5 & 0 & 2 & 0 & 0 & 0 & + & + & + & + & + & + & + & + \\
\hline 12 & $"$ & " & 1 & 0 & 2 & 0 & 0 & 0 & + & + & + & + & + & + & + & + \\
\hline 13 & $"$ & $"$ & 2 & 0 & 2 & 0 & 0 & 0 & + & + & + & + & + & + & + & + \\
\hline 14 & $"$ & ., & 1 & 0 & 0 & 0.5 & 0 & 0 & - & - & - & - & \pm & \pm & \pm & $\left.\pm^{1}\right)$ \\
\hline & ", & $"$ & 1 & 0 & 0 & 1 & 0 & 0 & - & - & - & - & - & - & - & - \\
\hline & $"$ & $"$ & 1 & 0 & 0 & 2 & 0 & 0 & - & - & - & - & - & - & - & - \\
\hline & $"$ & $"$ & 1 & 0 & 0 & 0 & 1 & 0 & + & + & + & + & + & + & + & + \\
\hline & $"$ & $"$ & 1 & 0 & 0 & 0 & 0 & 0.5 & - & + & + & + & + & + & + & + \\
\hline & & & 1 & 0 & 0 & 0 & 0 & 1.0 & -1 & + & + & + & + & + & + & $1+$ \\
\hline
\end{tabular}

The table shows that the production of indol takes place in the presence of peptone solution, glycerin, lactose, and starch; but saccharose and dextrose inhibit its production. In a second series of experiments B. coli and Prot. vulgaris were used for inoculation. The solutions were made up as in the first experiment and at the end of four days all the flasks were titrated against $\mathrm{n} / 10 \mathrm{NaOH}$. The results are given in Table No. 4.

Table No. 4.

Effect of carbohydrates on the production of indol.

\begin{tabular}{|c|c|c|c|c|c|c|c|c|c|c|c|c|c|c|c|c|}
\hline \multirow{2}{*}{ 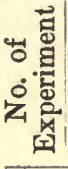 } & \multirow{2}{*}{$\begin{array}{l}\text { Or- } \\
\text { ganism }\end{array}$} & \multirow{2}{*}{ 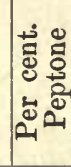 } & \multirow{2}{*}{ 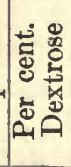 } & \multirow{2}{*}{ 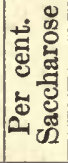 } & \multirow{2}{*}{ 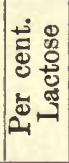 } & \multirow{2}{*}{ 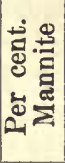 } & \multirow{2}{*}{ 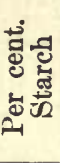 } & \multirow{2}{*}{ 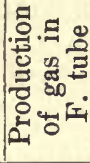 } & \multirow{2}{*}{ 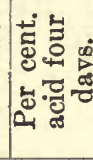 } & \multicolumn{7}{|c|}{ Indol produced } \\
\hline & & & & & & & & & & $24 \mid 48$ & $3|72| 96$ & & & & & 216 \\
\hline 1 & coli & 1 & 0 & 0 & 0 & 0 & 0 & - & 0 & -+ & ++ & + & + & + & + & 4 \\
\hline 2 & & 1 & 1 & 0 & 0 & 0 & 0 & + & 2.2 & -1 & $1-1$ & - & - & - & - & \\
\hline 3 & & 1 & ( & & 0 & 0 & 0 & + & 1.2 & -- & $-1-$ & - & - & -1 & - & - \\
\hline 4 & & 1 & ( & & 1 & 0 & 0 & + & 2 & $-1-$ & -1 & - & - & - & - & - \\
\hline 5 & 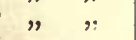 & 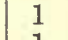 & & & 0 & 1 & & + & 2 & -- & & - & - & & - & - \\
\hline 6 & " " " & 1 & 0 & 0 & 0 & 0 & 1 & - & 0 & ++ & +1 & + & + & + & + & + \\
\hline 7 & vulg. I & 1 & ( & c & 0 & 0 & 0 & - & 0 & ++ & ++ & + & + & + & + & + \\
\hline 8 & & 1 & 1 & 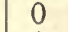 & 0 & 0 & & + & 1. & $-1-$ & -1 & - & - & - & - & - \\
\hline 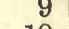 & & 1 & ( & & 0 & 0 & & + & 1. & $-1-$ & -- & - & - & - & - & 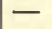 \\
\hline 1 & , & 1 & ( & 0 & 1 & 0 & & & 0 & ++ & +1 & + & + & + & + & + \\
\hline & & 1 & ( & c & 0 & 1 & & & 0 & $-1+$ & $+t$ & & & + & + & t \\
\hline 12 & & 1 & 0 & 0 & 0 & 0 & 1 & & 0 & $1-1+1$ & $1+1+$ & $1+$ & $1+$ & $1+1$ & $1+1$ & \\
\hline
\end{tabular}

The results indicate that in each case where acid is produced by the organism, there is an inhibition of indol production. Lactose, which

1) (I) doubtful. 
has no affect on indol production by $\mathrm{P}$. vulgaris, inhibits its production in the case of $\mathrm{B}$. coli as readily as does dextrose. This naturally leads to the conclusion that it is the acid and not the sugar which inhibits the production of indol.

An attempt was made to settle this point more definitely ly inoculating with P. vulgaris a sugar medium to which more than enough powdered marble had been added to neutralize the acid formed. It was found, however, that indol was not produced in any case where $1 \%$ or more of dextrose had been added to the medium. This seemed to disprove the conclusion that the inhibition of indol is due to the acid formed, but on titrating the solutions to which the marble had been added, it was found that the acid was being produced much faster than it was neutralized by the marble, so that even in this case the acid was probably the chief factor inhibiting the proteolytic action of the bacteria. As ordinary marble may contain some impurities, it was thought that the impurities in this substance may have had something to do with the results. To avoid this source of error, several flasks were prepared, each containing $100 \mathrm{c}$. c. of a $1 \%$ solution of peptone to which were added $1 \%$ of dextrose and more than enough chemically pure calcium carbonate to neutralize all acid formed, together with sufficient of a $1 \%$ azolitmin solution to give a blue color. The flasks were inoculated with Proteus vulgaris and incubated at $37^{\circ}$. In about 24 hours, the litmus had turned red. A flask prepared in the same manner was inoculated with B. coli and this also turned red. Flasks prepared in the same way without the addition of litmus and inoculated with B. coli or P. vulgaris, failed to produce indol in four days. The calcium carbonate, while reducing the amount of acid produced, did not keep the solution alkaline to litmus. Since acid sufficient to turn blue litmus red is able to inhibit the action of the tryptic ferment, calcium carbonate added to a medium is not sufficient to keep the degree of acidity low enough for the proteolytic ferment of P. vulgaris to act on the peptone. To obviate this difficulty a flask, prepared as in the other experiments, was inoculated with P. vulgaris and the acid was neutralized from time to time by the addition of a sterile solution of sodium carbonate to the medium. In this flask, indol was formed as soon as all the sugar had been used up. When lactic acid was added to the peptone solution which had been inoculated with P. vulgaris so that the solution was more than $0.5 \%$ acid, the production of indol was inhibited. When less than $0.5 \%$ was added, however, the production of indol was not appreciably delayed.

The above experiments seem to justify the conclusion that carbohydrates are more available to bacteria than are the proteins. In a medium containing sugar and protein substances, the sugar is usually the first attacked. When this is used up if the acid produced does not retard further action, the proteins are utilized. The inhibition of the proteolytic action is due to the acid formed and not to the sugar itself, for if the carbohydrate is not fermented the proteolytic action may not be retarded. The ferment produced by P. vulgaris seems to be a tryptic ferment.

\section{Effect of carbohydrates on gelatin liquefaction.}

Since the addition of certain carbohydrates to peptone solution inhibited the production of indol by P. vulgaris, it was thought that these sugars may also inhibit the power of these organisms to liquefy 
gelatin. Gelatin was made up in bulk and distributed to a series of flasks. One per cent. of carbohydrate was added to each flask, and the gelatin in the flasks was poured into tubes of equal diameter, so that each tube contained gelatin to a depth of $50 \mathrm{~m} . \mathrm{m}$. After sterilization, each tube was inoculated with the organism to be tested by spreading a suspension of the organism over the surface of the gelatin. The tubes were then placed in the incubator, kept at $22^{\circ} \mathrm{C}$ and allowed to remain for thirty days. At the end of the incubation period, the amount of liquefaction was determined by measuring the depth of the gelatin which had been reduced to a liquid state.

The results of the experiments are given in the table which follows.

Table No. 5.

Table showing the amount of liquefaction in millimeters in carbohydrate gelatin by members of the Proteus group.

\begin{tabular}{|c|c|c|c|c|c|c|c|c|c|c|c|}
\hline No. & & $\begin{array}{l}\text { Plain } \\
\text { Gel. }\end{array}$ & $\begin{array}{l}\text { Dex- } \\
\text { trose }\end{array}$ & $\begin{array}{c}\text { Saccha- } \\
\text { rose }\end{array}$ & $\begin{array}{l}\text { Levu- } \\
\text { lose }\end{array}$ & $\begin{array}{l}\text { Man- } \\
\text { nose }\end{array}$ & $\begin{array}{l}\text { Galac- } \\
\text { tose }\end{array}$ & $\begin{array}{l}\text { Mal- } \\
\text { tose }\end{array}$ & $\begin{array}{l}\text { Lac- } \\
\text { tose }\end{array}$ & $\begin{array}{c}\text { Raffi- } \\
\text { nose }\end{array}$ & $\underset{\text { nite }}{\text { Man- }}$ \\
\hline 1 & Prot. vulg. I & 50 & - & - & 5 & - & - & - & 50 & 1 & 40 \\
\hline 2 & $n \quad n$ II & 50 & - & - & 3 & 一 & - & - & 50 & - & 40 \\
\hline 3 & " mirabilis & 23 & 3 & - & - & - & - & - & 20 & - & 50 \\
\hline 4 & Zenkeri & - & - & - & - & - & - & - & - & $=$ & - \\
\hline 5 & B. cloacae I & 5 & 8 & 18 & 25 & 4 & 50 & 11 & 10 & 5 & 8 \\
\hline 6 & $n \quad n \quad$ II & 11 & 35 & 50 & 8 & 4 & 50 & 30 & 10 & 16 & 50 \\
\hline 7 & III & 11 & 12 & 35 & 25 & 25 & 40 & 30 & 30 & 25 & 50 \\
\hline 8 & $n \quad n \quad$ IV & 10 & 20 & 20 & 9 & 1 & 50 & 10 & 10 & 15 & 50 \\
\hline 9 & P. vulgaris & 30 & 2 & 2 & 19 & 3 & 5 & 3 & 50 & 20 & 50 \\
\hline 10 & P. mirabilis & - & - & - & - & - & - & - & - & - & - \\
\hline 11 & P. Zenkeri & - & $\overline{10}$ & $\overline{10}$ & $\overline{10}$ & $\overline{-}$ & $\overline{-}$ & $\overline{x-1}$ & $\overline{0}$ & - & $\overline{-0}$ \\
\hline 12 & B. cloacae & 12 & 12 & 19 & 10 & 15 & 40 & 14 & 20 & 4 & 50 \\
\hline 13 & B. vulgaris & 19 & - & - & - & - & - & - & 50 & - & 50 \\
\hline 14 & B. & 19 & - & - & - & - & $=$ & - & 15 & - & 50 \\
\hline 15 & B. Zopfi . & $\overline{01}$ & - & - & 西 & - & - & - & $\overline{0=}$ & - & $\overline{=0}$ \\
\hline 16 & B. vulgaris & 21 & - & - & 2 & - & $=$ & - & 35 & - & 50 \\
\hline 17 & B. mirabilis & 30 & - & - & 4 & 2 & 5 & 3 & 50 & - & 50 \\
\hline 18 & B. Zenkeri & - & - & - & - & - & - & - & & - & - \\
\hline 19 & B. cloacae & 25 & 5 & 12 & 10 & 15 & 40 & 16 & 25 & 17 & 40 \\
\hline 20 & P. vulgaris & 38 & - & - & - & 1 & 3 & - & 50 & - & 50 \\
\hline 21 & P. mirabilis & - & - & - & - & - & - & - & - & - & - \\
\hline 22 & P. Zenkeri & - & - & - & - & - & - & - & $\cdots$ & - & - \\
\hline 23 & P. Zopfi & - & - & $=$ & $=$ & $\overline{50}$ & $\overline{50}$ & $\overline{0 \pi}$ & $\overline{0}$ & $\overline{0=}$ & $\overline{-0}$ \\
\hline 24 & IB. cloacae & 20 & 26 & 50 & 50 & 50 & 50 & 25 & 18 & 25 & 50 \\
\hline
\end{tabular}

The table shows that dextrose, saccharose, levulose, mannose, galactose, maltose, and raffinose, tend to inhibit the liquefaction of gelatin by all strains of P. vulgaris and by P. mirabilis, 3 and 17 , while gelatin containing lactose or mannite do not retard the liquefaction of gelatin. All of the strains of P. Zenkeri, P. Zopfii, and mirabilis, with the exception of P. mirabilis 3 and 17 , did not liquefy gelatin in any of the tubes, even when allowed to remain in the incubator for three months. It was found that sugars which inhibited the gelatin liquefaction by Proteus vulgaris were fermented by that organism.

To find out whether acid was produced by the fermentation of the sugars in the gelatin tubes, a second series of sugar gelatin tubes were prepared and a few drops of $1 \%$ solution of azolitmin were added to each, as well as to the nutrient gelatin control. The tubes were inoculated with P. vulgaris as in the previous experiment and incubated at $22^{\circ} \mathrm{C}$. In every tube which showed liquefaction, the litmus remained 
blue, but in all cases where gelatin was not liquified, turned decidedly red. The acid formed by the fermentation of the sugar is probably therefore, the chief factor at work in preventing gelatin liquefaction by P. vulgaris.

In view of the experiments of 0 gata (29), Laborde (30), Goldthwait (31) and Lindsay (32), in which these authors seem to have demonstrated that the addition of carbohydrates to artificial digestion solutions retards the digestion of protein substances, it would seem that sugars themselves should retard the proteolytic action of bacterial ferments as well. Bearing in mind that these authors, experiments were conducted with peptic ferments, the idea might be entertained that sugars likewise exert some retarding effect in the presence of tryptic ferments such as are produced by P. vulgaris. That the mere presence of sugar is not effective, however, is conclusively demonstrated by the following experiments.

A flask containing 50 c. c. of nutrient gelatin with a reaction neutral to phenolphthalein was inoculated with P. vulgaris I and allowed to stand until completely liquefied. A portion of the liquefied gelatin was passed through a hard filter to remove the bacteria. Two series of flasks were prepared as indicated in the following table. To each of the first series of flasks one c.c. of the unfiltered gelatin was added, while to each of the second series of flasks 1 c. c. of the filtered gelatin was added. Both series were allowed to stand under the same conditions. The results for the sake of convenience are given in tabulated form.

1. 50 c. c. nutrient gelatin $+2 \%$ dextrose +1 c. c. filtered gelatin = no liquefaction in

20 days.
2. $50 \mathrm{c}$.
$n+2 \% \quad n$
+1 c. c. filtered gelatin = liquefaction in 4
3. 50 c. c.
$n+2 \% \quad n$
4. 50 c.c.
n $+2 \%$ lactose
+1 c. c. unfiltered gelatin +1 c. c. filtered
, $+2 \%$ n
5. 50 c. c.
$n$
6. 50 c.c.
7. 50 c.c.
$n$
8. 50 c. c.
$n+2 \% \mathrm{HCl}$
gelatin $=$ no liquefaction in 8 days.
+1 c. c. unfiltered gelatin = liquefaction in 4 days.
+1 c. c. filtered gelatin = liquefaction in 4 days.
+1 c. c. unfiltered gelatin = liquefaction in 4 days.
+1 c. c. filtered gelatin = liquefaction in 4 days.
+1 c. c. filtered gelatin $=$ no liquefaction in 10 days.

All the flasks were tested at the completion of the experiments and pure cultures of P. v.ulgaris were found in all of the flasks to which the unfiltered gelatin had been added while those flasks which had received the filtered gelatin proved sterile. Flasks one and three developed an acid reaction while the reaction of the other flasks remained unchanged.

The results are striking and conclusive. In those flasks to which acid had been added or which developed an acid reaction no liquefaction resulted, while in the flasks in which no acid was produced liquefaction took place at a fairly uniform rate. There can be but one interpretation of these results: the liquefaction of the gelatin was inhibited by the acid. We know from the above experiments that dextrose has no effect upon the proteolytic ferment when formed. If to the dextrose gelatin we add in addition to the filtered gelatin a suspension of Prote u $\mathrm{v}$ v l$\mathrm{g}$ a ris we get no liquefaction. In this case, however, the bacteria attacked 
the dextrose, acid was formed and this acid inhibited the proteolytic action. Whether or not the presence of dextrose or the acid produced from dextrose prevents the formation of the proteolytic enzyme is not evident from these experiments, though it seems probable that dextrose alone would not be capable of exerting such an influence.

B. cloacae, unlike P. vulgaris, is able to liquefy gelatin in the presence of all the sugars tried. It was noted, however, that the liquefaction in the case of $B$. cloacae did not begin as quickly in the sugar gelatin tubes as in the nutrient gelatin tubes, though when it did begin it proceeded further in some cases. An initial acid production takes place in sugar gelatin tubes inoculated with B. cloacae since litmus added to these tubes turned red after 48 hours incubation at $22^{\circ}$ C. Evidently, a small amount of acid does not interfere with the proteolytic action of B. cloacae to any great extent. Since it was shown in a previous paper (33) that the initial acidity produced by B. cloacae in a sugar protein medium may be followed by alkalinity, it is possible that the amido compounds produced by the proteolytic action of this organism tend to neutralize the acid produced, and thus keep the percentage of acid low enough to enable the proteolytic ferment to work, or the proteolytic ferment of $\mathrm{B}$. cloaca may be more resistant to acid than is the ferment of P. vulgaris. This is suggestive that the proteolytic ferment of $B$. cloacae is more peptic than tryptic.

An attempt was made to cause the non-gelatin liquefiers to liquefy gelatin by growing them in nutrient gelatin for varying lengths of time under different degrees of temperature. Some gelatin cultures were placed in the $37^{\circ}$ incubator and allowed to remain there for six days. The gelatin was then placed in the ice box to see if it would solidify again. The tubes on solidifying, were plated out in gelatin and ten characteristic colonies were selected and inoculated into gelatin tubes. These were allowed to stand for six days and again plated out and selections made from the colonies on the plate. Although this process was carried on through several transfers, not a single culture was obtained which would liquefy nutrient gelatin when allowed to stand at $22^{\circ}$ for 30 days. All the gelatin tubes inoculated with the nonliquefiers and kept in the $37^{\circ}$ incubator solidified again when placed in the ice box for a short time. The colonies on the gelatin plates were characteristic only when the gelatin was moist. If the percentage of gelatin in the medium was high, the characteristic Proteus colonies did not always develop.

The fact that Proteus Zenkeri and Proteus mirabilis do not liquefy gelatin readily or at all is hardly sufficient reason to classify these organisms as species distinct from Proteus vulgaris. Some authors have made the observation that a species of P. Z enkeri which had repeatedly failed to liquefy gelatin suddenly developed this power, while Smith (5) was able to obtain a non-gelatin liquefier from $P$. vulgaris. These facts would indicate that P. Zenkeri and P. mira$\mathrm{b}$ ilis and $\mathrm{Zopfii}$ are varieties of $\mathrm{P}$. vulgaris which have lost many of their enzymotic powers but have developed no new characteristics which would be sufficient to call them distinct species. P. Zopfii and P. Zenkeri, together with the strains of P. mirabilis which do not liquefy gelatin, all belong undoubtedly to the same variety, P. Z enkeri, and the names $\mathrm{Z}$ opfii and mirabilis could very well be done away with. The strains of $\mathrm{P}$. mirabilis are at best intermediate forms 
between vulgaris and Zenkeri, which need but cultivation to turn them into P. vulgaris on the one hand or P. Zenkeri on the other. The morphological characteristics are of little use in the differentiation of these organisms since under artificial conditions either may produce short rods or longs filaments, according to the kind of media used and the condition under which they are grown. P. vulgaris in all strains was negative to Gram, while P. Zenkeri was usually positive, but even this characteristic is so variable that it has no characteristic value.

None of the species of Proteus examined produced any pigment. This test was made on potato, $\mathrm{Heinemanns}$ synthetic medium, and on agar, to which $1 \%$ of tyrosin had been added. In the latter medium, P. vulgaris produced a dark coloration in the medium in about 24 hours, but no pigment was developed.

\section{Conclusions.}

1. Selection of slight variations in acid production in sugar broth by $\mathrm{P}$. vulgaris failed to produce any variation in the acid producing properties of this organism.

2. P. vulgaris, though not able to ferment lactose under aerobic conditions, does so when cultivated under anaerobic conditions.

3. Carbohydrates, when fermented by P. vulgaris or B. coli, inhibit the production of indol, by these organisms. The inhibition is, however, due to the acid formed and not to the carbohydrate itself.

4. The addition of more than $0,5 \%$ of lactic acid to the culture medium inhibits the production of indol.

5. The acid formed by the fermentation of carbohydrates inhibits to a certain degree the liquefaction of gelatin by members of the Proteus group.

6. The ferment formed by P. vulgaris seems to be a tryptic ferment, while that of $B$. cloacae is suggestive of a peptic ferment.

7. P. Zopfii and Zenkeri are probably one and the same variety, and P. mirabilis seems to be an intermediate form between Zenkeri and vulgaris which differs in the intensity of its biochemical reactions, but not in the quality. Some strains of mirabilis examined gave similar biochemical reactions to those of $\mathrm{P}$. Z $\mathrm{Znkeri}$, while others resembled P. vulgaris very closely.

The writer takes great pleasure in thanking Professors E. O. J or d a n and Norman MacL. Harris for their suggestions and encouragement in this work.

\section{References.}

1) Ann. d. l'Inst. Pasteur. Vol. 6. 1892. p. 512.

2) Zeitschr. f. Hyg. Bd. 17. 1894. p. 1.

3) Lancet. Vol. 11. 1906. p. 708.

4) Journ. Boston Soc. Med. Sc. Vol. 4. 1900. p. 170.

5) Journ. Exper. Med. Vol. 2. 1897. p. 543.

6) Journ. Exper. Med. Vol. 2. 1897. p. 549.

7) Proc. Roy. Soc. Vol. 79. 1897. p. 320. 
8) Journ. infect. Dis. Vol. 5. 1908. p. 379.

9) Münchn. med. Wochenschr. No. 39. 1902. p. 103.

10) Centralbl. f. Bakt. Bd. 8. 1890. p. 789.

11) Johns Hopkins Hosp. Bull. Vol. 4. 1893. p. 34.

12) Johns Hopkins Hosp. Bull. Vol. 5. 1894. p. 24.

13) Arch. f. exper. Path. u. Pharmakol. Bd. 34. 1894. p. 342.

14) Zeitschr. f. Hyg. Bd. 27. 1898. p. 143.

15) Zeitschr. f. Hyg. Bd. 30. 1899. p. 328.

16) Centralbl. f. Bakt. Abt. I. Bd. 25. 1899. p. 696.

17) Rendic. d. R. Accad. d. Lincei. Vol. 5. 1899. p. 125.

18) Ann. of Bot. Vol. 13. 1899. p. 197.

19) Journ. Med. Research. Vol. 4. 1899. p. 609.

20) Journ. Med. Research. Vol. 6. 1901. p. 211.

21) Journ. Hyg. Vol. 3. 1903. p. 7.

22) Journ. infect. Dis. Vol. 5. 1908. p. 421.

23) Journ. infect. Dis. Vol. 6. 1909. p. 90.

24) Arch. f. Hyg. Bd. 31. 1897. p. 311.

25) Arch. f. Hyg. Bd. 37. 1900. p. 30.

26) Centralbl. f. Bakt. Abt. I. Orig. Bd. 30. 1901. p, 244.

27) Journ. infect. Dis. Vol. 2. 1905. p. 309.

28) Journ. Hyg. Vol. 7. 1907. p. 581 .

29) Arch. f. Hyg. Bd. 3. 1885. p. 211.

30) Journ. de Pharm. et Chimie. Vol. 10. 1899. p. 484.

31) Journ. Biol. Chem. Vol. 7. 1910. p. 69.

32) Science. Vol. 31. 1910. p. 311.

33) Journ. infect. Dis. Vol. 6. 1909. p. 339. 



YD 23390

236712 
